\title{
Acid sphingomyelinase inhibition protects mice from lung edema and lethal Staphylococcus aureus sepsis
}

\author{
Huiming Peng • Cao Li • Stephanie Kadow • Brian D. Henry • Jörg Steinmann • \\ Katrin Anne Becker • Andrea Riehle • Natalie Beckmann • Barbara Wilker • Pin-Lan Li • \\ Timothy Pritts • Michael J. Edwards • Yang Zhang • Erich Gulbins • Heike Grassmé
}

Received: 20 June 2014 / Accepted: 17 December 2014 / Published online: 25 January 2015

(C) The Author(s) 2015. This article is published with open access at Springerlink.com

\begin{abstract}
Pulmonary edema associated with increased vascular permeability is a severe complication of Staphylococcus aureus-induced sepsis and an important cause of human pathology and death. We investigated the role of the mammalian acid sphingomyelinase (Asm)/ceramide system in the development of lung edema caused by $S$. aureus. Our findings demonstrate that genetic deficiency or pharmacologic inhibition of Asm reduced lung edema in mice infected with $S$. aureus. The Asm/ceramide system triggered the formation of superoxide, resulting in degradation of tight junction proteins followed by lung edema. Treatment of infected mice with amitriptyline, a potent inhibitor of Asm, protected mice from lung edema caused by S. aureus, but did not reduce systemic bacterial numbers. In turn, treatment with antibiotics reduced bacterial numbers but did not protect mice from lung edema. In contrast, only the combination of
\end{abstract}

Electronic supplementary material The online version of this article (doi:10.1007/s00109-014-1246-y) contains supplementary material, which is available to authorized users.

H. Peng $\cdot$ C. Li $\cdot$ S. Kadow $\cdot$ B. D. Henry $\cdot$ K. A. Becker $\cdot$

A. Riehle $\cdot$ N. Beckmann $\cdot$ B. Wilker $\cdot$ E. Gulbins $(\triangle) \cdot$

H. Grassmé $(\bowtie)$

Department of Molecular Biology, University of Duisburg-Essen,

Hufelandstrasse 55, 45122 Essen, Germany

e-mail: erich.gulbins@uni-due.de

e-mail: heike.gulbins@uni-due.de

J. Steinmann

Department of Medical Microbiology, University of Duisburg-Essen, Virchowstrasse 179, 45147 Essen, Germany

B. D. Henry $•$ T. Pritts $\cdot$ M. J. Edwards $\cdot$ E. Gulbins

Department of Surgery, University of Cincinnati, Cincinnati, $\mathrm{OH} 45267$, USA

P.-L. Li • Y. Zhang

Department of Pharmacology and Toxicology, Medical College of Virginia, Virginia Commonwealth University, Richmond, VA 23298, USA antibiotics and amitriptyline inhibited both pulmonary edema and bacteremia protecting mice from lethal sepsis and lung dysfunction suggesting the combination of both drugs as novel treatment option for sepsis.

\section{Key messages}

- Antibiotics are often insufficient to cure S. aureus-induced sepsis.

- S. aureus induces lung edema via the Asm/ceramide system.

- Genetic deficiency of Asm inhibits lung dysfunction upon infection with $S$. aureus.

- Pharmacologic inhibition of Asm reduces lung edema induced by $S$. aureus.

- Antibiotics plus amitriptyline protect mice from lung edema and lethal $S$. aureus sepsis.

Keywords Acid sphingomyelinase/ceramide system $\cdot$ Lung edema $\cdot$ Superoxide $\cdot$ Staphylococcus aureus

\section{Introduction}

Although Staphylococcus aureus (S. aureus) is a commensal of the skin, it is also one of the most serious pathogens and often causes not only local purulent wound infections of the skin and soft tissues but also severe diseases such as pneumonia, endocarditis, osteomyelitis, sepsis, and toxic shock syndrome $[1,2]$. In particular, the methicillin-resistant $S$. aureus (MRSA) strains are increasing in importance, particularly in hospitals [3, 4]. In the United States, S. aureus is responsible for approximately 500,000 infections and 20,000 deaths each year [5]. A dreaded complication of $S$. aureus-induced sepsis 
is lung edema, which is often fatal. Damage to the endothelium and disruption of tight junctions (TJs) are central to the pathophysiology of lung edema and sepsis after systemic infection with S. aureus [6, 7].

It has been previously shown that the interaction of $S$. aureus with endothelial cells depends on the activation of mammalian acid sphingomyelinase (Asm) [8]. The Asm is an ubiquitous enzyme, which is expressed in all cells including myeloid cells [9]. Asm hydrolyzes sphingomyelin, which is the most prominent sphingolipid in the membrane, to ceramide [10]. Ceramide has been shown to spontaneously form distinct domains in the plasma membrane leading to the formation of ceramide-rich platforms. Those platforms serve to trap and cluster receptor molecules, thereby permitting and amplifying signal transduction $[11,12]$. This process may lead to subsequent apoptosis of the endothelial cells upon infection with S. aureus. However, several other pathogens besides $S$. aureus, such as Neisseria gonorrhoeae, Listeria monocytogenes, Pseudomonas aeruginosa, Salmonella typhimurium, Escherichia coli, and Mycobacterium avium, also exploit the Asm/ceramide system to infect mammalian cells [13-18]. The Asm/ceramide system has been shown to be involved in internalization of these pathogens, the induction of host cell apoptosis, the activation of intracellular signaling pathways, and the control of the release of cytokines.

The Asm/ceramide system is also crucially involved in killing bacteria, predominantly by facilitating the activation of NADPH oxidases. Ceramide domains cluster subunits of NADPH oxidases, thereby releasing superoxide after the infection of macrophages [19]. Although superoxide is necessary for killing bacteria, the results of previous studies also indicate that superoxide molecules contribute to $S$. aureusinduced dysfunction of the lung endothelial cell barrier [20]. The family of NADPH oxidases appears to be the predominant contributor of endothelial superoxide, which is activated by several stimuli and involved in diverse pathways, including endothelial cell activation and inflammation [21].

Here, we investigated the role of Asm in S. aureus-induced lung edema. Our findings provide evidence that the Asm/ ceramide system plays a central role in S. aureus-induced pulmonary edema via induction of superoxide and thereby destruction of TJ proteins. Genetic or pharmacologic inhibition of Asm or production of superoxide reduced lung injury after $S$. aureus infection. Pharmacologic inhibition of Asm with amitriptyline, a functional inhibitor of the enzyme, inhibited lung edema but did not reduce bacterial numbers in mice infected with $S$. aureus. Antibiotics reduced bacterial numbers but did not protect mice from lung edema, a finding consistent with the clinical observation that patients with $S$. aureus sepsis experience severe lung edema despite treatment with antibiotics. Treating infected mice with a combination of antibiotics and amitriptyline reduced both pulmonary edema and bacteremia, thus protecting mice from lethal sepsis and lung dysfunction.

\section{Materials and methods}

Mice and cells

Acid-sphingomyelinase (Asm)-deficient mice (sphingomyelin phosphodiesterase 1 knockout; Smpdl ${ }^{-/-}$) and syngenic wild-type (wt) littermates on a C57BL/6J genetic background were kindly provided by Dr. R. Kolesnick (Memorial Sloan-Kettering Cancer Center, New York, NY, USA). Mice were maintained in the animal facility of the University Duisburg-Essen under pathogen-free conditions according to the criteria of the Federation of Laboratory Animal Science. The genotype was verified by PCR analysis before experimentation. For all experiments, we used mice only aged 6 to 8 weeks, which do not show an accumulation of myeloid cells, mostly macrophages, in the lung (Fig. 1c, noninfected sample). Further, the concentrations of TNF- $\alpha$ and IL-1 did not differ in lungs of 6-week-old wt and Asmdeficient mice (not shown). Infection experiments were approved by the Landesamt für Natur, Umwelt und Verbraucherschutz (LANUV), animal grant G1376/13 and local authorities.

For pretreatment with inhibitors before infection, wt mice were injected intraperitoneally with $10 \mathrm{mg} / \mathrm{kg}$ amitriptyline (Sigma-Aldrich, Deisenhofen, Germany), $100 \mathrm{mg} / \mathrm{kg}$ Tiron (Fluka Chemie GmbH, Buchs, Germany), or $100 \mathrm{mg} / \mathrm{kg}$ NAC (Sigma) twice daily for 2.5 days. The last dose was given $1 \mathrm{~h}$ before infection. For treatment with amitriptyline post infection, wt mice were injected i.p. 1 or $2 \mathrm{~h}$ after infection with $16 \mathrm{mg} / \mathrm{kg}$ amitriptyline. Antibiotics were also injected i.p. $1 \mathrm{~h}$ after infection with $100 \mathrm{mg} / \mathrm{kg}$ methicillin (Sigma) or $100 \mathrm{mg} / \mathrm{kg}$ vancomycin (Sigma). The injection of methicillin or vancomycin was repeated $9 \mathrm{~h}$ after infection. All mice, either pretreated with inhibitors or post-treated with amitriptyline and/or antibiotics, were sacrificed after 12 or $24 \mathrm{~h}$. For survival experiments, we administered $16 \mathrm{mg} / \mathrm{kg}$ amitriptyline $1 \mathrm{~h}$ after infection and reduced to $10 \mathrm{mg} / \mathrm{kg}$ amitriptyline in the following injection after $12 \mathrm{~h}$ and then twice daily until $144 \mathrm{~h}$ post-infection. The antibiotics vancomycin and methicillin were administered twice daily $(100 \mathrm{mg} / \mathrm{kg})$, starting 12 and $24 \mathrm{~h}$ after infection until $144 \mathrm{~h}$ post-infection.

The in vitro experiments were performed with murine EOMA endothelial cells (ATCC ${ }^{\circledR}$ CRL-2586 ${ }^{\mathrm{TM}}$ ), which were maintained in Dulbecco's modified Eagle's medium (DMEM) (Gibco/Invitrogen, Karlsruhe, Germany) supplemented with $10 \%$ fetal calf serum (PAA, Pasching, Austria, A15-101), 10 mM HEPES (Roth GmbH, Karlsruhe, Germany), pH 7.4, 2 mML-glutamine, $1 \mathrm{mM}$ sodium pyruvate, $100 \mu \mathrm{M}$ non-essential amino acids, $100 \mathrm{U} / \mathrm{ml}$ penicillin, and $100 \mu \mathrm{g} / \mathrm{ml}$ streptomycin (all from Thermo Fisher Scientific, Waltham, USA) at $37^{\circ} \mathrm{C}$ in a $10 \% \mathrm{CO}_{2}$ atmosphere. 
Infection experiments

All in vivo and in vitro infections were performed with a clinical $S$. aureus strain isolated from a patient with sepsis. Further characterization of the strain showed that it produces alpha-toxin and enterotoxin D but not the Panton-Valentine leukocidin or toxic shock syndrome toxins. To exclude strainspecific results, we repeated the principal experiments with the well-characterized $S$. aureus sepsis strain Newman (ATCC ${ }^{\circledR}$ 25904) [43].

Bacteria were grown overnight on trypticase soy agar plates supplemented with $5 \%$ sheep blood (BD Biosciences, Heidelberg, Germany). The plates were incubated for $16 \mathrm{~h}$ at $37{ }^{\circ} \mathrm{C}$. Bacteria were then resuspended in prewarmed trypticase soy broth (TSB; BD) at an optical density $(550 \mathrm{~nm})$ of $0.2 / \mathrm{ml}$, shaken at $125 \mathrm{rpm}$ for $70 \mathrm{~min}$ at $37^{\circ} \mathrm{C}$, and collected during the early logarithmic growth phase by centrifugation at $3000 \mathrm{rpm}$ for $10 \mathrm{~min}$. The bacterial pellet was washed twice in DMEM supplemented with $10 \mathrm{mM}$ HEPES (Roth GmbH, Karlsruhe, Germany) or phosphate buffered saline (PBS, $137 \mathrm{mM} \mathrm{NaCl}, 2.7 \mathrm{mM} \mathrm{KCl}, 7 \mathrm{mM} \mathrm{CaCl}$, $0.8 \mathrm{mM} \mathrm{MgSO}_{4}, 1.4 \mathrm{mM} \mathrm{KH}{ }_{2} \mathrm{PO}_{4}$, and $6.5 \mathrm{mM} \mathrm{Na}_{2} \mathrm{HPO}_{4}$ ) and then resuspended at $9 \times 10^{8}$ colony-forming units (CFU) per milliliter of DMEM supplemented with $10 \mathrm{mM}$ HEPES for infection of EOMA cells or at $5 \times 10^{6} \mathrm{CFU}$ per $100 \mu \mathrm{l}$ in PBS for infection of mice.

EOMA cells were infected in DMEM/10 mM HEPES. We added $20 \mu \mathrm{M}$ amitriptyline, $10 \mathrm{mM}$ Tiron, or $10 \mathrm{mM}$ NAC $20 \mathrm{~min}$ before infection and inoculated sub-confluent cell layers at a bacteria-to-host cell ratio (multiplicity of infection, MOI) of 10:1 or 200:1. Synchronous infection conditions and enhanced interactions between bacteria and host cells were achieved by a 2-min centrifugation $(1000 \mathrm{rpm})$ of the bacteria onto the cells. The end of the centrifugation was defined as the starting point of infection. The infection was terminated by fixation or lysis, as described below.

To infect the mice, we intravenously injected $5 \times 10^{6} \mathrm{CFU}$ S. aureus. After the indicated time, the animals were sacrificed by cervical dislocation, and the lung, spleen, or liver was removed for further processing. To determine the amount of Evans Blue leakage into lung tissue, we injected mice intravenously with $4 \%$ Evans Blue dye (20 mg/kg, Sigma) $30 \mathrm{~min}$ before sacrificing the mice (infection time $12 \mathrm{~h}$ ); lungs were flushed with saline via the right heart, removed, dried, extracted in formamide (Sigma), centrifuged, and supernatants were measured at 620 and $740 \mathrm{~nm}$ with a fluorescence microplate reader (BMG Labtech, Offenburg, Germany). To determine neutrophil immigration capacity, we infected mice with $5 \times$ $10^{6}$ CFU S. aureus i.p. for $2 \mathrm{~h}$, sacrificed them, and injected ice-cold PBS into the peritoneal cavity. Peritoneum was then gently massaged and PBS was aspirated from the peritoneal cavity. The cell number was counted and $1 \mathrm{ml}$ cell suspension was preincubated with anti-CD16/CD32 mAb (Biolegend, clone 93) to block FcRII/III receptors and stained for $15 \mathrm{~min}$ at $4{ }^{\circ} \mathrm{C}$ with FITC-anti-mouse Ly-6G (Gr1) (eBioscience, clone RB6-8C5), PE-Cy7-anti-mouse CD11b (eBioscience, clone $\mathrm{M} 1 / 70$ ), and APC-anti-mouse F4/80 (eBioscience, clone BM8). Cells were analyzed using FACS Calibur ${ }^{\mathrm{TM}}$ (BD Bioscience) and absolute numbers were calculated.

Assay for acid sphingomyelinase activity

The activity of Asm was measured as the conversion of radioactive $\left[{ }^{14} \mathrm{C}\right]$-sphingomyelin to ceramide and $\left[{ }^{14} \mathrm{C}\right]$ phosphorylcholine. Then $8 \times 10^{5}$ EOMA cells were infected with $S$. aureus for the indicated time periods, washed, and lysed in $300 \mu$ ice-cold Asm lysis buffer [1 \% NP-40, $250 \mathrm{mM}$ sodium acetate ( $\mathrm{pH}$ 5.0)] per sample, aliquots diluted to $0.1 \% \mathrm{NP}-40$ and $250 \mathrm{mM}$ sodium acetate $(\mathrm{pH} 5.0)$, and incubated with $\left[{ }^{14} \mathrm{C}\right]$-sphingomyelin (Perkin Elmer, specific activity $=2 \mathrm{GBq} / \mathrm{mmol}$ ) for $30 \mathrm{~min}$ at $37{ }^{\circ} \mathrm{C}$. $\left[{ }^{14} \mathrm{C}\right]$ sphingomyelin was dried prior to use and solubilized into micelles in $0.1 \%$ NP-40, $250 \mathrm{mM}$ sodium acetate ( $\mathrm{pH} 5.0$ ) using a bath sonicator for $10 \mathrm{~min}$. Samples were normalized for protein using Bradford assays.

Cell lysates were incubated for $60 \mathrm{~min}$ with $0.05 \mu \mathrm{Ci}\left[{ }^{14} \mathrm{C}\right]-$ labeled sphingomyelin per sample at $37{ }^{\circ} \mathrm{C}$ with a thermomixer (Eppendorf AG, Hamburg, Germany). Lipids were then extracted by the addition of $1 \mathrm{ml} \mathrm{CHCl} / \mathrm{CH}_{3} \mathrm{OH}$ $(2: 1, \mathrm{v} / \mathrm{v})$ per sample, followed by vortexing for $15 \mathrm{~s}$ and centrifugation at $14,000 \mathrm{rpm}$ for $5 \mathrm{~min}$. An aliquot of the aqueous phase was applied for liquid scintillation counting. Hydrolysis of $\left[{ }^{14} \mathrm{C}\right]$-sphingomyelin by Asm results in the release of $\left[{ }^{14} \mathrm{C}\right]$-choline chloride into the aqueous phase, whereas ceramide and unreacted $\left[{ }^{14} \mathrm{C}\right]$-sphingomyelin remain in the organic phase. Therefore, the release of $\left[{ }^{14} \mathrm{C}\right]$-choline chloride serves to determine the activity of Asm.

\section{Ceramide measurements}

Ceramide was measured using a DAG kinase assay, as previously described $[15,17]$. Briefly, cells were infected for the indicated time and then extracted in $\mathrm{CHCl}_{3} / \mathrm{CH}_{3} \mathrm{OH} / 1 \mathrm{~N} \mathrm{HCl}$ (100:100:1, v/v/v). The organic phase was collected and dried lipids were solubilized in $20 \mu \mathrm{l}$ of $7.5 \% \mathrm{~N}$-octyl glucopyranoside, $5 \mathrm{mM}$ cardiolipin, $1 \mathrm{mM}$ DETAPAC and sonicated in a bath sonicator for $10 \mathrm{~min}$. We then added $50 \mu \mathrm{l}$ DAG kinase reaction buffer $[100 \mathrm{mM}$ imidazole/ $\mathrm{HCl}$ (pH 6.6), $100 \mathrm{mM} \mathrm{NaCl}, 25 \mathrm{mM} \mathrm{MgCl} 2,2 \mathrm{mM}$ EDTA, $2.8 \mathrm{mM}$ DTT, $5 \mu \mathrm{M}$ ATP, $\left.10 \mu \mathrm{Ci}\left[{ }^{32} \mathrm{P}\right]-\gamma \mathrm{ATP}\right]$ and $0.01 \mathrm{U}$ DAG kinase (BML-SE100; Enzo Life Sciences, USA) in $10 \mu \mathrm{l}$ of $1 \mathrm{mM}$ DETAPAC ( $\mathrm{pH}$ 6.6) and $0.01 \mathrm{M}$ imidazole. The kinase reaction was performed for $30 \mathrm{~min}$ at room temperature.

The samples were then re-extracted in $1 \mathrm{ml} \mathrm{CHCl}_{3} /$ $\mathrm{CH}_{3} \mathrm{OH} / 1 \mathrm{~N} \mathrm{HCl}(100: 100: 1, \mathrm{v} / \mathrm{v} / \mathrm{v}), 170 \mu \mathrm{l}$ buffered salt 
solution $\left[135 \mathrm{mM} \mathrm{NaCl}, 1.5 \mathrm{mM} \mathrm{CaCl}_{2}, 0.5 \mathrm{mM} \mathrm{MgCl}\right.$, $5.6 \mathrm{mM}$ glucose, $10 \mathrm{mM}$ HEPES (pH 7.2)], and $30 \mu \mathrm{l}$ of a $100 \mathrm{mM}$ EDTA solution per sample, followed by vortexing. The lower organic phase was concentrated, and dried lipids were dissolved in $20 \mu \mathrm{CHCl}_{3} / \mathrm{CH}_{3} \mathrm{OH}(1: 1, \mathrm{v} / \mathrm{v})$ per sample and separated on a Silica G60 thin layer chromatography (TLC) plate (Merck, Darmstadt, Germany) with a solvent system consisting of $\mathrm{CHCl}_{3} / \mathrm{CH}_{3} \mathrm{COCH}_{3} / \mathrm{CH}_{3} \mathrm{OH} /$ $\mathrm{CH}_{3} \mathrm{COOH} / \mathrm{H}_{2} \mathrm{O}(10: 4: 3: 2: 1, \mathrm{v} / \mathrm{v} / \mathrm{v} / \mathrm{v} / \mathrm{v})$. The plate was analyzed using a Fuji phosphoimager. Ceramide spots were identified by co-migration with a $\mathrm{C}_{16} / \mathrm{C}_{24}$-ceramide standard. Comparison with a standard curve for $\mathrm{C}_{16} / \mathrm{C}_{24}$-ceramide permitted the determination of ceramide amounts.

To determine local accumulation of ceramide after infection, EOMA cells were infected with $S$. aureus (MOI 10:1) for 40 min, washed twice in PBS, and fixed with $1 \%$ PFA in buffered PBS ( $\mathrm{pH} 7.3$ ) for $15 \mathrm{~min}$. The cells were then washed in PBS, permeabilized for 10 min with $0.1 \%$ Triton X-100 in PBS, washed in PBS, blocked with an irrelevant affinitypurified donkey antibody (Jackson; 1:100 in PBS $+0.025 \%$ Tween 20) for $60 \mathrm{~min}$ at room temperature, washed three times with PBS $+0.025 \%$ Tween 20, and incubated with a rabbit anti-S. aureus antibody (Abcam 20920; 1:500 in PBS+ $0.025 \%$ Tween $20+5 \%$ FCS) for $60 \mathrm{~min}$ at room temperature. The cells were then washed three times with PBS+ $0.025 \%$ Tween 20 and incubated with Alexa-Fluor 647coupled anti-rabbit Ig (Jackson; 1:500 in PBS $+0.025 \%$ Tween $20+5 \%$ FCS) overnight at $4{ }^{\circ} \mathrm{C}$. The samples were washed again three times, blocked again as above, washed three times followed by a 60 -min staining at room temperature with mouse monoclonal anti-ceramide IgM (Glycobiotech MAB 0011; 1:100 in PBS $+0.025 \%$ Tween 20+5 \% FCS). The samples were washed three times, stained with $\mathrm{Cy} 3-$ labeled anti-mouse IgM (Jackson; 1:500 in PBS $+0.025 \%$ Tween $20+5 \%$ FCS) for $60 \mathrm{~min}$ at room temperature, washed three times, and embedded in Mowiol (Kuraray Specialities Europe GmbH, Frankfurt, Germany). The samples were analyzed by confocal microscopy using a Leica TCS SL microscope (Leica, Mannheim, Germany).

\section{Measurement of production of superoxide}

Superoxide production was measured by electron spin resonance (ESR), as described previously [31]. Then $2 \times 10^{5}$ endothelial cells were infected with $S$. aureus for the indicated time, the medium removed, the cells scraped into $20 \mathrm{mM}$ HEPES (pH 7.5), $1 \mathrm{mM}$ EDTA, and $255 \mathrm{mM}$ sucrose, and shock frozen in liquid nitrogen. Proteins were isolated and resuspended with modified Krebs-HEPES buffer containing deferoximine $(100 \mu \mathrm{M}$, Sigma) and diethyldithiocarbamate (5 $\mu \mathrm{M}$, Sigma). A spin trap, 1-hydroxy-3-methoxycarbonyl-2, 2,5,5-tetramethylpyrrolidine (CMH, Noxygen, Elzach, Germany) (1 mM final concentration), was then added to the mixture in the presence or absence of manganese-dependent superoxide dismutase (SOD, $200 \mathrm{U} / \mathrm{ml}$; Sigma, St. Louis, $\mathrm{MO})$. The mixture was loaded into glass capillaries and immediately kinetically analyzed for $\mathrm{O}_{2}^{-}$production for $10 \mathrm{~min}$. The SOD-inhibited fraction of the signal was used to calibrate the system. The ESR settings were as follows: biofield, 3350; field sweep, $60 \mathrm{G}$; microwave frequency, $9.78 \mathrm{GHz}$; microwave power, $20 \mathrm{~mW}$; modulation amplitude, $3 \mathrm{G}$; points of resolution, 4096; receiver gain, 100; and kinetic time, $10 \mathrm{~min}$. The ESR signal strength was recorded in arbitrary units and the final results were expressed as the fold changes compared to the control.

Immunocytochemistry

Cells were grown on coverslips, infected or left uninfected, fixed in $2 \%$ paraformaldehyde (PFA, Sigma) buffered in PBS (pH 7.2-7.4) for $10 \mathrm{~min}$, and washed in PBS. For intracellular staining of $\mathrm{ZO} 1, \mathrm{ZO} 2$, occludin, and E-cadherin, cells were permeabilized with $0.1 \%$ Triton X-100 (Sigma) in PBS (pH 7.4) for $5 \mathrm{~min}$ at room temperature, washed with PBS, and blocked for $1 \mathrm{~h}$ in PBS supplemented with $5 \%$ fetal calf serum (FCS, Gibco). Samples were washed and incubated overnight at $4{ }^{\circ} \mathrm{C}$ with antibodies against ZO1 (Invitrogen 40-2300, rabbit IgG), ZO2 (Santa Cruz Biotechnology Inc. sc-11448, rabbit $\operatorname{IgG}$ ), occludin (71-1500, rabbit IgG, Invitrogen), or E-cadherin (Santa Cruz Biotechnology Inc. sc-7870, rabbit IgG). Cells were washed three times in PBS with $0.05 \%$ Tween 20 (Sigma), incubated for $1 \mathrm{~h}$ with Cy3-labeled donkey anti-rabbit antibodies, and washed again in PBS with $0.05 \%$ Tween 20. After a final wash with PBS, cells were mounted on glass coverslips with Mowiol. Cells were examined with a Leica TCS SP5 confocal microscope (Leica, Mannheim, Germany) using Leica software, version 2.61 .

\section{Histopathologic assessment}

Mice were sacrificed, the lungs were removed, fixed in $4 \%$ PFA for $38 \mathrm{~h}$, serially dehydrated, and embedded in paraffin for sectioning at $6 \mu \mathrm{m}$. For stainings, sections were dewaxed and rehydrated. H\&E staining was performed by incubating lung sections in hematoxylin for $2 \mathrm{~min}$ and in eosin for $1 \mathrm{~min}$. For fluorescence staining, lung sections were incubated in pepsin (Invitrogen) for $20 \mathrm{~min}$ at $37^{\circ} \mathrm{C}$, washed, and treated for $10 \mathrm{~min}$ in PBS supplemented with $5 \% \mathrm{FCS}$ and $0.5 \%$ Tween 20. Lung sections were exposed overnight at $4{ }^{\circ} \mathrm{C}$ to anti-ZO1 IgG, anti-ZO2 IgG, anti-E-cadherin IgG, antioccludin IgG, or anti-Ly-6G and Ly-6C (Gr-1, rat IgG; BD) antibodies (all antibodies as above). The sections were washed in PBS with $0.05 \%$ Tween 20 and then incubated for an additional $45 \mathrm{~min}$ with $\mathrm{Cy} 3$-labeled secondary antibodies 
(Jackson ImmunoResearch, West Grove, PA, USA). For costainings of TJs and endothelial cells, samples were incubated together with antibodies against ZO1, ZO2, occludin, and Ecadherin additionally with FITC-Lectin (Fluorescein Griffona Simplicifolia Lectin I-Isolectin B $_{4}$, Vector, FL-1201, 1:50) and then proceeded as above. The sections were washed once in PBS with $0.05 \%$ Tween 20 and once in PBS and were mounted in Mowiol. Lung samples were analyzed by light transmission or confocal microscopy.

Quantification of S. aureus colony-forming units in liver, spleen, and lung

To quantify $S$. aureus colony-forming units (CFU), we removed the liver, spleen, and lung from each mouse after the indicated time of infection and homogenized them in a loose Dounce homogenizer (Braun, Germany). The homogenates were lysed for $10 \mathrm{~min}$ in $5 \mathrm{mg} / \mathrm{ml}$ saponin (Serva Electrophoresis $\mathrm{GmbH}$, Heidelberg, Germany) at $37{ }^{\circ} \mathrm{C}$ for the release of intracellular bacteria. Samples were centrifuged for $10 \mathrm{~min}$ at $3200 \mathrm{rpm}$, resuspended in PBS, and plated on lysogeny broth (LB) plates. Bacterial CFU were counted after the plates had been incubated overnight at $37^{\circ} \mathrm{C}$.

\section{Statistical analysis}

All data are displayed as mean $\pm \mathrm{SD}$. All data were tested for normal distribution using the David-Pearson-Stephens test. Statistical analysis was performed with Student's $t$ test for single comparisons and ANOVA for multiple comparisons. Groups in the survival tests were compared by log-rank test. The sample size planning for the continuous in $S$. aureus in vivo infections experiments was based on two-sided Wilcoxon-Mann-Whitney tests using the free software $G^{*}$ Power version 3.1.7 of the University of Dusseldorf, Germany. Statistical significance was set at the level of $P$ $<0.05$.

\section{Results}

Acid sphingomyelinase deficiency reduces $S$. aureus-induced lung edema

To determine whether Asm plays a role in the in vivo development of lung edema caused by $S$. aureus infection, we systemically infected C57BL/6 wild-type (wt) and Asmdeficient mice with $S$. aureus for various time periods. To quantify lung edema, we injected the dye Evans Blue, which leaks into the lung only if the endothelial cell integrity is disrupted and thereby serves to quantify lung edema in vivo. The studies revealed massive leakage of Evans Blue dye into the lungs of wt mice but almost no leakage into the lungs of Asm-deficient mice after systemic infection with a clinical S. aureus strain (Fig. 1a) or S. aureus Newman (supporting Fig. 1A). Moreover, hematoxylin and eosin (H\&E) staining of the lungs demonstrated that $S$. aureus infection induces lung edema in wt mice as indicated by thick hyaline walls in large venules and massive cellular infiltrates, findings that were absent or much less pronounced in Asm-deficient mice (Fig. 1b and supporting Fig. 1B, C). The absence of lung edema in Asm-deficient mice correlated with a reduced number of myeloid cells in the lungs of Asm-deficient mice, while high numbers of GR1-positive, myeloid cells were observed in the lungs of $S$. aureus-infected wt mice (Fig. 1c, d). Controls revealed that Asm deficiency did not affect the ability of myeloid cells to migrate (supporting Fig. 1D), but reduced the production of superoxide in myeloid cells (supporting Fig. 1E).

Taken together, these findings indicate that Asm plays a key role in the development of pulmonary edema induced by systemic infection with $S$. aureus. Asm deficiency inhibits the development of lung injury during infection.

Infection of endothelial cells with $S$. aureus activates Asm and leads to the production of superoxide in a positive feedback loop

To further define the role of the Asm in lung edema induced by systemic infections with $S$. aureus, we infected murine endothelial (EOMA) cells with $S$. aureus and measured Asm activity. $S$. aureus infection induced a marked activation of the Asm (Fig. 2a and supporting Fig. 2A) and formation of ceramide (Fig. 2b and supporting Fig. 2B), the product of Asm activity.

Superoxide has long been known to play a crucial role in host-pathogen interactions [20, 22, 23]. To determine whether $S$. aureus infection also induces the release of superoxide and whether this superoxide release depends on Asm, we infected EOMA cells and analyzed the production of oxygen radicals. The results showed that $S$. aureus infection induces a rapid production of superoxide in EOMA cells (Fig. 2c and supporting Fig. 2C). Infection with a lower multiplicity of infection (MOI) of $S$. aureus revealed a similar but slightly delayed time course of Asm activation (Fig. 2d), intracellular ceramide accumulation at the site of $S$. aureus internalization (Fig. 2e), and superoxide release (Fig. 2f). Pre-incubation of EOMA cells with the antioxidants Tiron and $N$-acetylcysteine (NAC) reduced Asm activation by $S$. aureus (Fig. 2d). Preincubation of EOMA cells with the functional Asm inhibitor amitriptyline (Ami) [17, 24, 26] or with Tiron and NAC also inhibited superoxide release (Fig. 2c, f and supporting Fig. 2C) suggesting a positive feedback loop of S. aureusinduced Asm activation and superoxide release. 


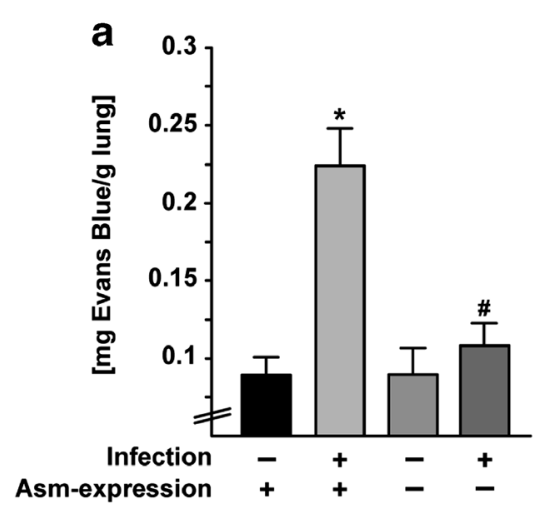

b

Inf. time [h]

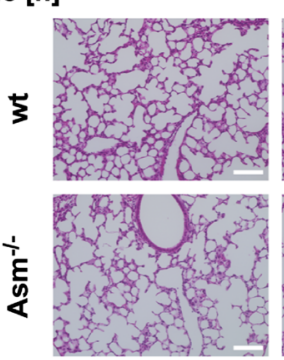

4
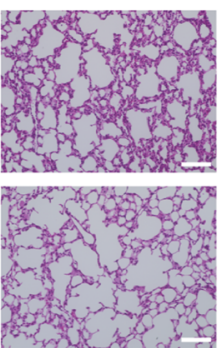

C

Infection time [h]
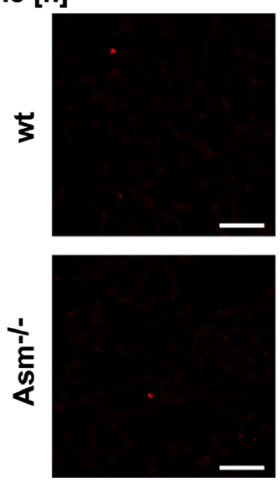

Fig. 1 Acid sphingomyelinase deficiency protects against $S$. aureusinduced lung edema. a Wild-type (wt) and acid sphingomyelinase (Asm)-deficient mice were infected with $S$. aureus for $12 \mathrm{~h}$. Evans Blue dye was injected $30 \mathrm{~min}$ before sacrificing the mice and removal of the lungs. The amount of dye leaking into the lung tissue was quantified. Shown are the mean \pm SD of the concentration of Evans Blue dye in the lungs from each five wt and Asm-deficient mice. *Significant differences between uninfected mice and infected mice; \#significant differences between infected wt mice and Asm-deficient mice (all $P<0.05$; ANOVA). b Wt and Asm-deficient $\left(\mathrm{Asm}^{-/}\right)$mice were infected with $S$. aureus for the indicated time periods. They were sacrificed, and lung sections were stained with H\&E and analyzed by light microscopy for the detection of

S. aureus induces degradation of TJs via the Asm/ceramide system

To gain insight into the mechanism by which Asm and ceramide mediate endothelial dysfunction and lung edema after S. aureus infection, we determined whether systemic infection

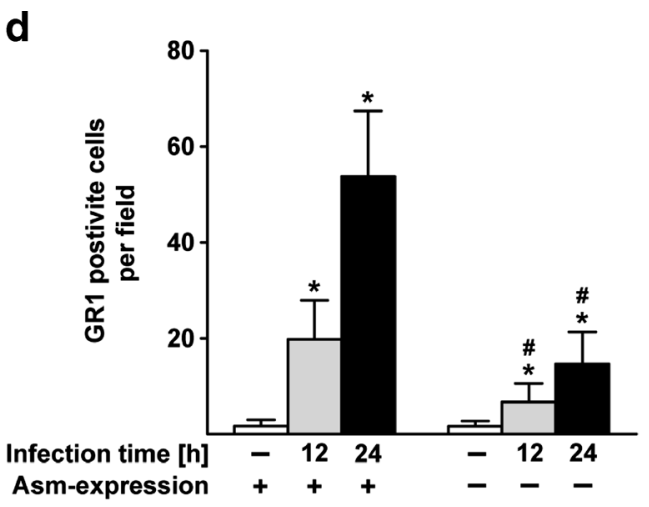

8

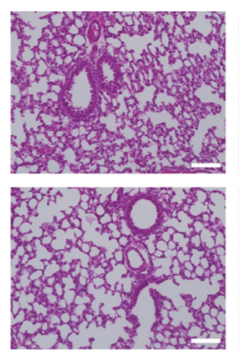

12
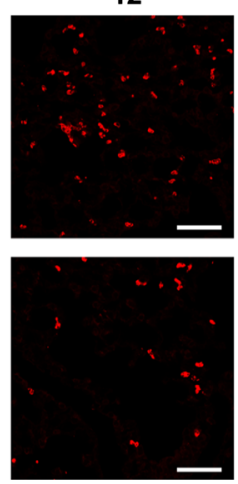

12

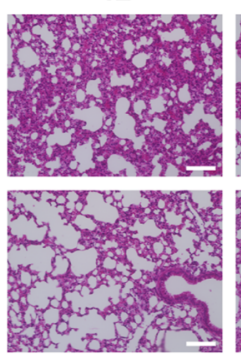

24
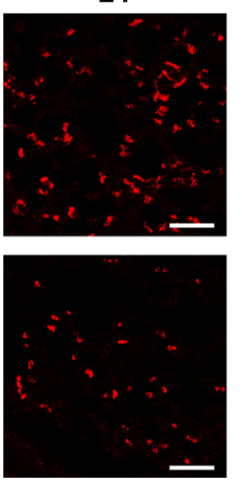

lung edema. Scale bar is $100 \mu \mathrm{m}$. Representative images from three independent experiments are shown. $\mathbf{c}, \mathbf{d}$ For determination of pulmonary myeloid cell influx, wt and Asm-deficient mice were left uninfected or were infected with $S$. aureus for 12 or $24 \mathrm{~h}$. Lung sections were stained with Cy3-labeled anti-GR1 antibodies and analyzed by fluorescence microscopy. Scale bar is $50 \mu \mathrm{m}$. Shown are representative images from three independent experiments. Cells staining positive for GR1, a myeloid cell marker, were quantified by analysis of 50 fields per group. Shown is the number (mean $\pm \mathrm{SD}$ ) of GR1-positive cells using a 630fold magnification. *Significant differences between uninfected mice and infected mice; \#significant differences between infected wt mice and Asm-deficient mice (all $P<0.05 ; t$ test).

with $S$. aureus induces the breakdown of TJs in pulmonary endothelial cells in vivo and, if so, whether this process depends on the Asm/ceramide system. To this end, we systemically infected wt and Asm-deficient mice with S. aureus. We then obtained lung sections and stained them with Cy3labeled antibodies to ZO1, ZO2, occludin, or E-cadherin. 


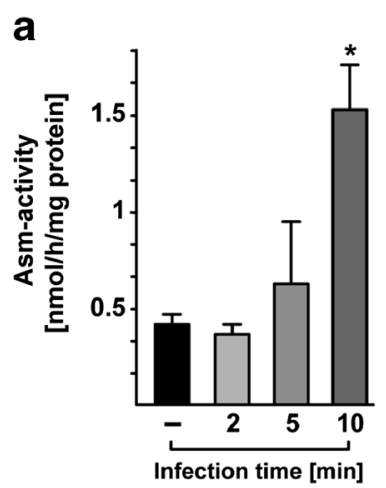

d

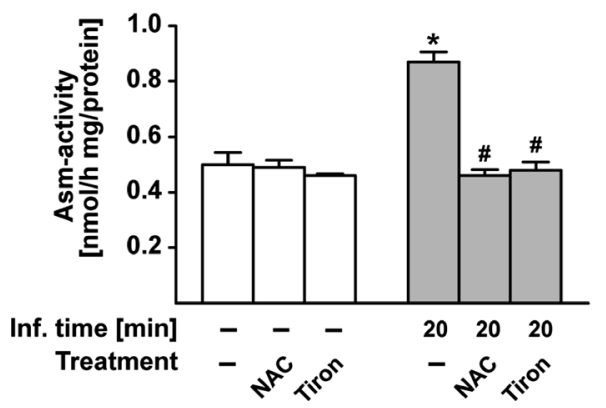

b

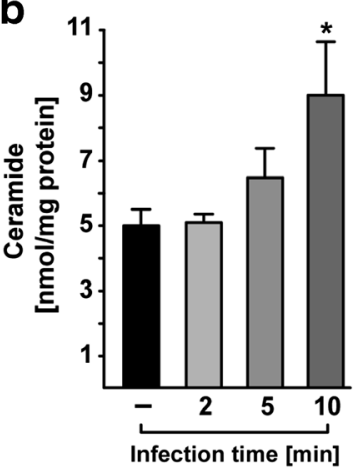

C

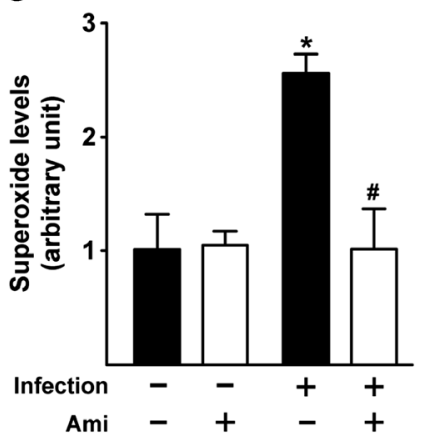

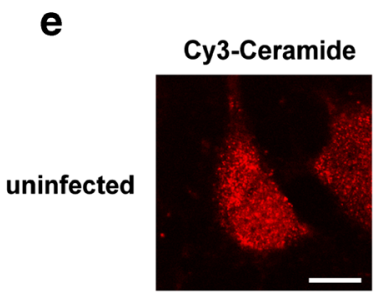

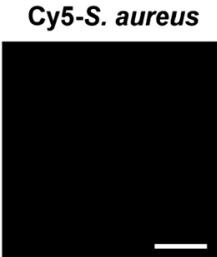

f

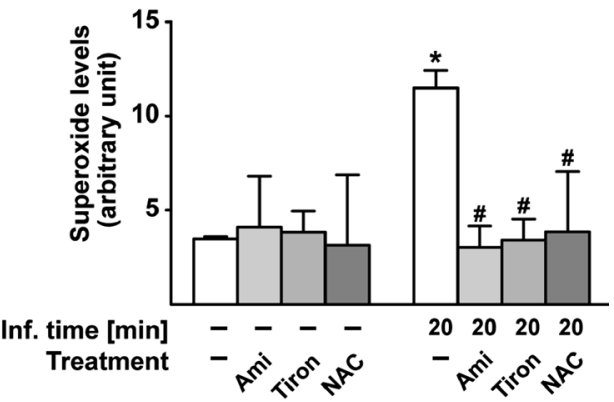

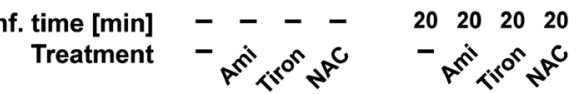
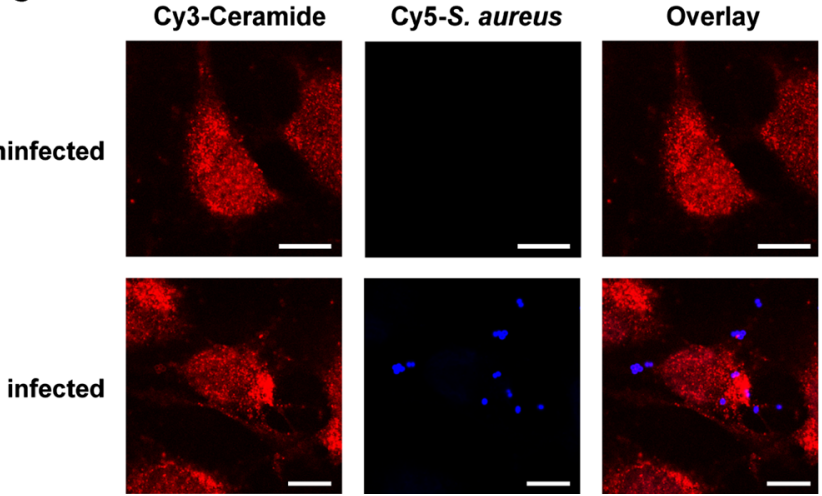

Fig. 2 Asm is necessary for S. aureus-induced production of superoxide. a, b Asm activity (a) and ceramide concentrations (b) were measured in EOMA cells after infection with $S$. aureus for $0,2,5$, or 10 min at an MOI of 200:1. Results show the mean \pm SD of three independent experiments. * Significant differences compared to uninfected control mice $(P<0.05, t$ test). c EOMA cells were infected with $S$. aureus for 7.5 min at an MOI of 200:1. The production of superoxide was quantified by electron spin resonance. Relative $\mathrm{O}_{2}{ }^{-\cdot}$ levels were used to indicate superoxide accumulation. Shown are means \pm SD from four independent experiments. *Significant differences between uninfected samples and infected samples; \#significant differences between untreated samples and amitriptyline (Ami)-treated samples (all $P<0.05$, ANOVA). d-f Infection

with a lower MOI (10:1) of S. aureus also resulted in Asm activation (d), ceramide accumulation at the site of $S$. aureus infection (e), and superoxide release (f). Pre-incubation of EOMA cells with the antioxidants Tiron and $N$-acetylcysteine (NAC) (each $10 \mathrm{mM}$ ) reduced Asm activation (d). Pre-incubation of EOMA cells with the functional Asm inhibitor amitriptyline or with antioxidants also inhibited superoxide release (f). Shown are means of arbitrary units \pm SD or representative figures from four independent experiments. Scale bar is $10 \mu \mathrm{m}$. *Significant differences between uninfected samples and infected samples; \#significant differences between untreated and treated samples (all $P<0.05$, ANOVA). Figures 3 and 4. S. aureus induces disruption of TJs in endothelial cells via Asm-mediated superoxide production

Confocal microscopy showed that infection with $S$. aureus induces dramatic degradation of $\mathrm{TJ}$ proteins in a timedependent manner in endothelial cells from blood vessels in wt lungs but not in endothelial cells from the lungs of Asmdeficient mice or wt mice pretreated with amitriptyline (Fig. 3a-d and supporting Fig. 3A-H). Co-stainings of lung sections with Cy3-coupled antibodies against TJs and FITCisolectin $\mathrm{B}_{4}$, which is a marker for endothelial cells, confirmed that $\mathrm{TJ}$ proteins are only degraded in lung endothelial cells of wt mice upon infection with $S$. aureus, but not in Asmdeficient endothelial cells [25] (Fig. 3e, f and supporting Fig. 4A-F). 
Fig. 3 Wild-type (wt) and Asmdeficient mice $\left(\mathrm{Asm}^{-/}\right)$were left uninfected or were infected with $S$. aureus for the indicated time points. Wt mice were pretreated before infection with amitriptyline (Ami) $(10 \mathrm{mg} / \mathrm{kg})$ or the antioxidants Tiron $(100 \mathrm{mg} / \mathrm{kg})$ and $\mathrm{N}$-acetylcysteine (NAC) $(100 \mathrm{mg} / \mathrm{kg})$, or left untreated and/or uninfected. Lung sections were stained with Cy3-coupled antibodies against E-cadherin (a, c) or co-stained for cadherin and the endothelial cells marker FITC-lectin (e, f) and analyzed by confocal microscopy for determination of the degradation of these TJ proteins. Representative images from three independent experiments are shown [original image and an area of interest (AOI)]. Scale bar is $10 \mu \mathrm{m}$. To score TJ protein fluorescence, we focused on one large vessel, chose the strongest fluorescence, and analyzed signal intensity in ten pictures per lung. The investigators were blinded to the identity of the samples $(\mathbf{b}, \mathbf{d}) . *$ Significant differences between uninfected and infected samples; \#significant differences between wt and Asmdeficient or untreated and treated samples (all $P<0.05$, ANOVA). a

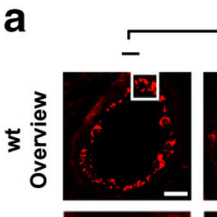

Infection time [h]
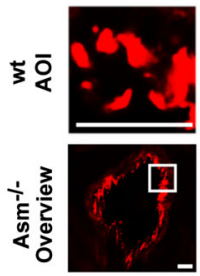

7)
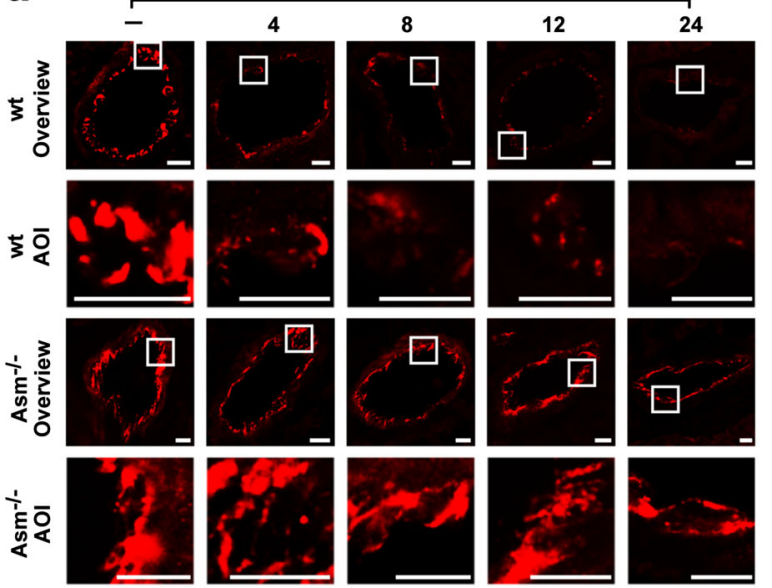

C

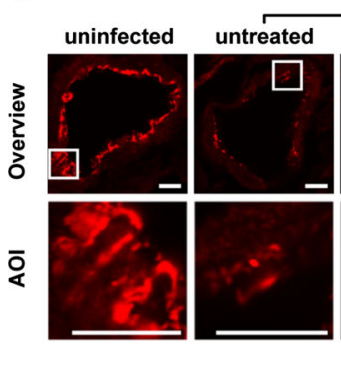

infected (12 hrs)
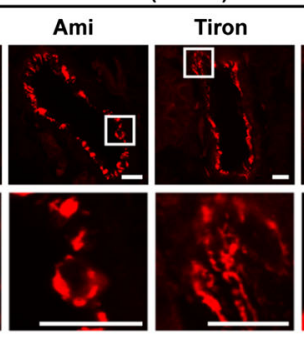

e

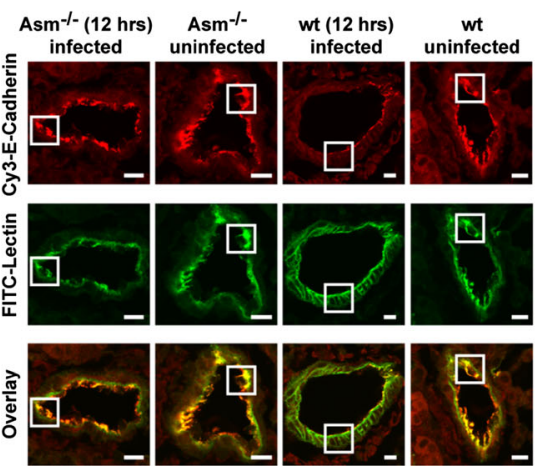

24
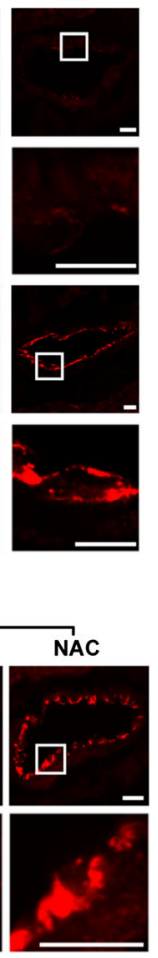

d

b
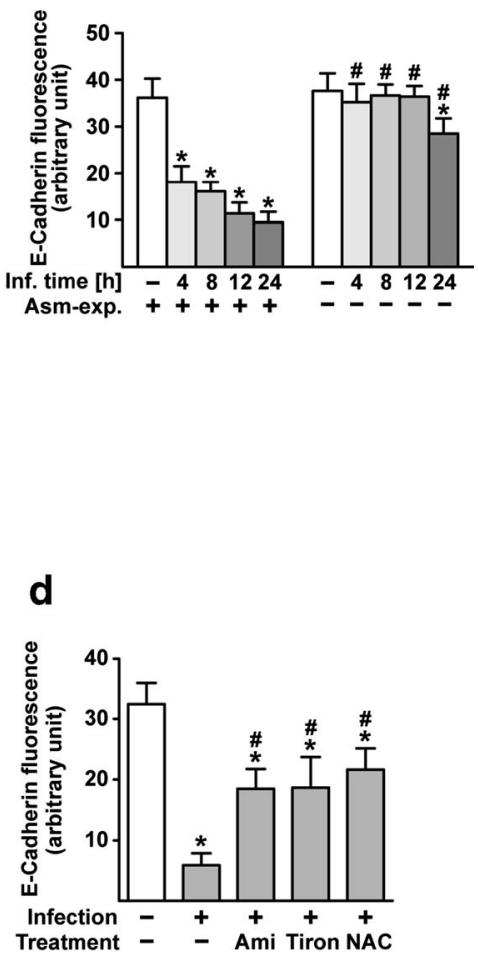

f

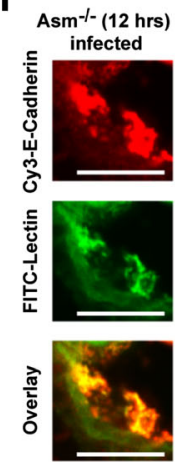

\section{Treatment}
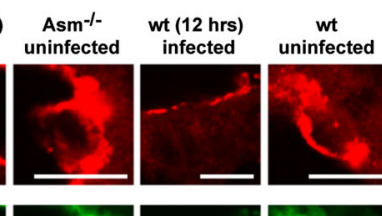
uninfected
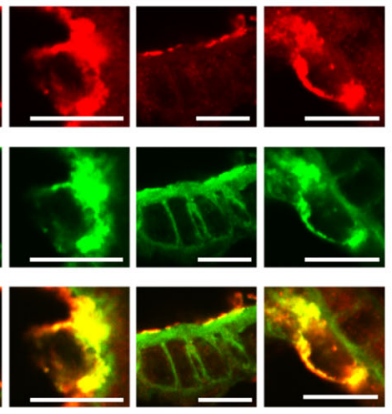

To determine whether TJs degradation pre-supposes the production of superoxide, we pretreated wt mice with intraperitoneal injections of both Tiron or NAC and then infected them with $S$. aureus. Confocal microscopy analysis demonstrated that the inhibition of superoxide also protects TJ proteins in endothelial cells from degradation after systemic $S$. aureus infection in vivo (Fig. $3 \mathrm{c}, \mathrm{d}$ and supporting Fig. 3B, D, F, H). The in vivo findings were confirmed by in vitro studies: infecting EOMA cells with $S$. aureus induces a marked degradation of the TJ proteins $\mathrm{ZO} 1, \mathrm{ZO} 2$, occludin, and E-cadherin, changes that were reduced by pre-incubation with inhibition of the Asm by amitriptyline or superoxides by NAC or Tiron (Fig. 4 and supporting Fig. 5A, B).

Collectively, these findings suggest that Asm mediates the $S$. aureus-induced breakdown of $\mathrm{TJ}$ proteins by superoxide in vivo.
Pharmacologic inhibition of Asm or superoxide reduces lung edema after systemic infection with $S$. aureus

To test the significance of the pathway from the Asm via superoxide to the degradation of $\mathrm{TJ}$ proteins and the development of lung edema, we treated wt mice with intraperitoneal injections of amitriptyline or the antioxidants Tiron and NAC before systemic infection with $S$. aureus and then measured lung edema and myeloid cell influx after 12 h. S. aureus infection induced severe lung edema and influx of myeloid cells into the lung, events that were inhibited by pretreatment with amitriptyline, Tiron or NAC (Fig. 5a-d). These findings show that lung edema induced by $S$. aureus via the pathway through Asm and superoxide can be reduced by pretreatment with pharmacologic inhibitors of this pathway. 
Fig. 4 Endothelial cells were infected for $2 \mathrm{~h}$ with $S$. aureus (MOI 10:1) or left uninfected. As indicated, cells were pretreated for $20 \mathrm{~min}$ with amitriptyline (Ami) $(20 \mu \mathrm{M})$, Tiron $(10 \mathrm{mM})$, or NAC $(10 \mathrm{mM})$ before infection with $S$. aureus. Immunofluorescence stainings were performed with antibodies against ZO1, $\mathrm{ZO}$ 2, occludin, or E-cadherin for determination of the degradation of these TJ proteins. The presented pictures are representative of the results of at least three independent experiments. Scale bar is $25 \mu \mathrm{m}$

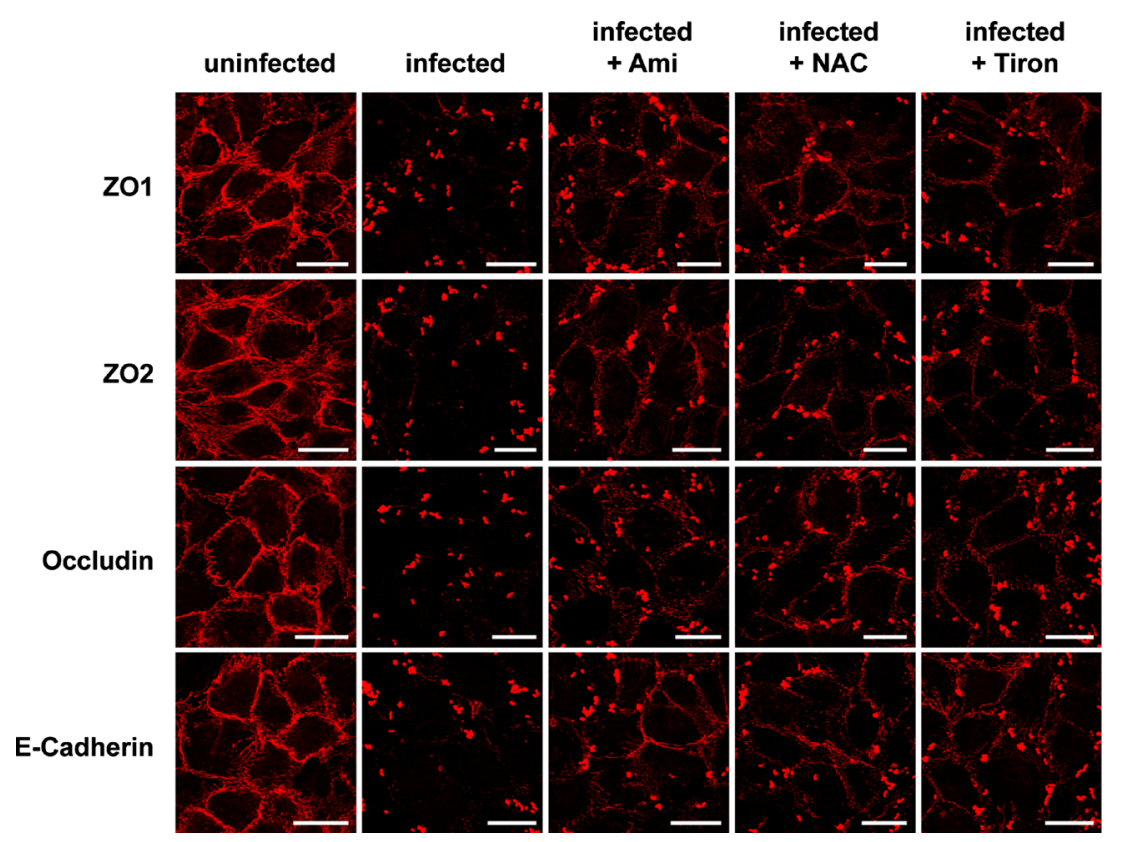

Treatment of already septic mice with amitriptyline reduces the development of lung edema

The finding that both pre-incubation with the Asm inhibitor amitriptyline and Asm deficiency protect mice from lung edema induced by $S$. aureus infection led us to question whether the administration of amitriptyline reduces the severity of pulmonary edema in mice that were already infected with S. aureus. If so, amitriptyline administration might be a clinically relevant therapeutic option for the treatment of $S$. aureus -induced pulmonary edema. To this end, we infected wt mice with $S$. aureus and treated them with amitriptyline (Ami) 1 or $2 \mathrm{~h}$ later. The mice were sacrificed $12 \mathrm{~h}$ after infection and Evans Blue extravasation into lung tissue was determined or lung sections were stained with H\&E. Treatment with amitriptyline reduced the severity of pulmonary edema and the influx of myeloid cells even after the onset of systemic infection with $S$. aureus (Fig. 6a-d) and the breakdown of TJ proteins (Fig. 6e, f and supporting Fig. 6A-D).

Thus, treatment with amitriptyline reduces the severity of lung edema even when the drug is administered 1 or $2 \mathrm{~h}$ after systemic infection with $S$. aureus.

The combination of amitriptyline and antibiotics inhibits sepsis

Clinically, treating S. aureus sepsis with antibiotics achieves only limited success, and severe lung edema often still develops even with appropriate antibiotic treatment [27-29]. Thus, with the aim of developing novel efficient therapeutic approaches to the treatment of $S$. aureus-induced sepsis and lung edema, we examined the effect of a combination of amitriptyline and antibiotics on bacterial killing and lung edema after systemic $S$. aureus infection. To this end, we infected wt mice with S. aureus. With the incidence of first clinical symptoms $1 \mathrm{~h}$ after infection, amitriptyline or methicillin or vancomycin or a combination of amitriptyline and either methicillin or vancomycin were injected. The injection of methicillin or vancomycin was repeated after $9 \mathrm{~h}$. Control mice were left uninfected. The mice were sacrificed $24 \mathrm{~h}$ after infection, and bacterial numbers were determined in liver, spleen, and lung.

While antibiotics alone or in combination with amitriptyline kill bacteria in liver, spleen, and lung, neither methicillin nor vancomycin alone reduced lung edema. In contrast, amitriptyline alone inhibited lung edema but did not reduce bacterial numbers. Only the combination of amitriptyline with antibiotics reduced bacteremia, lung edema, pulmonary influx of myeloid cells, and disruption of tight junctions (Fig. 7a-f; supporting Fig. 7A-F; supporting Fig. 8A-G). Control studies confirmed that the drugs were without effect on lung parameters in uninfected mice (supporting Fig. 9A-F).

These findings indicate that treating $S$. aureus infection with a combination of amitriptyline and antibiotics might be an effective clinical treatment for $S$. aureus-induced sepsis because such treatment reduced both bacterial burden and lung edema.

The pharmacological treatment of lung edema and bacterial burden protects from lethality of $S$. aureus sepsis

To investigate the link between bacterial burden and sepsisinduced lethality, we performed mortality experiments with 

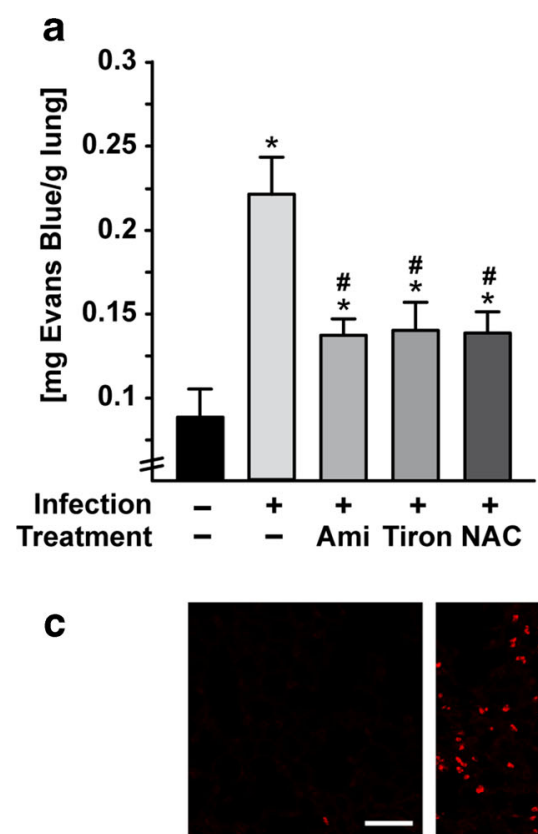

uninfected

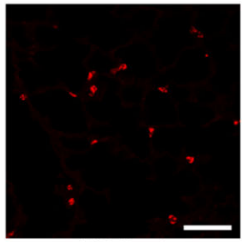

(12 hrs) infected+Ami

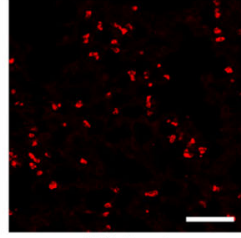

(12 hrs) infected+untreated

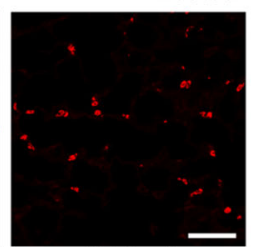

(12 hrs) infected+Tiron b

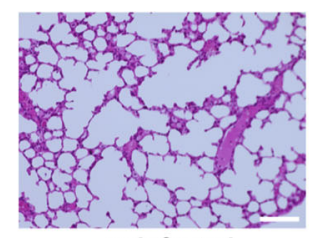

uninfected

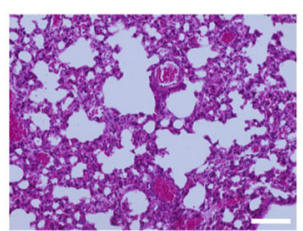

(12 hrs) infected

+ untreated

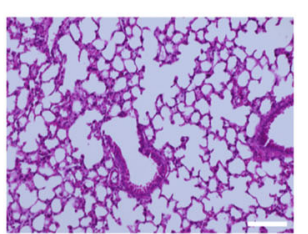

(12 hrs) infected+Ami

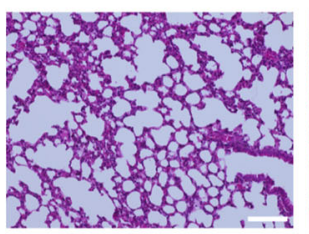

(12 hrs) infected+Tiron

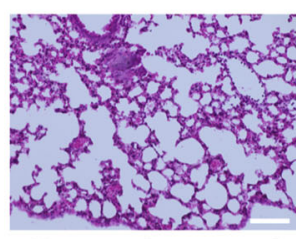

(12 hrs) infected+NAC

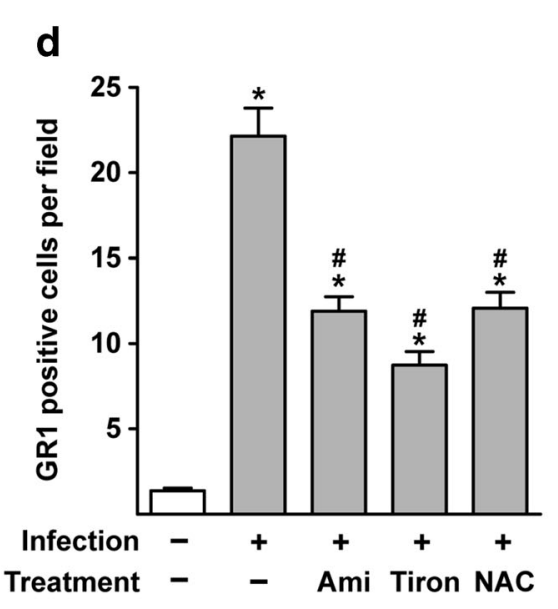

Fig. 5 Pharmacologic inhibition of acid sphingomyelinase (Asm) or superoxide reduces pulmonary edema caused by systemic infection with S. aureus. Wild-type (wt) mice were pretreated by intraperitoneal injection of $10 \mathrm{mg} / \mathrm{kg}$ amitriptyline (Ami) or $100 \mathrm{mg} / \mathrm{kg}$ Tiron $/ \mathrm{N}$ acetylcysteine (NAC), respectively. Mice were infected with $S$. aureus for $12 \mathrm{~h}$. Lung edema was determined by extravasation of Evans Blue (a) and by staining with H\&E (scale bar is $100 \mu \mathrm{m}$ ) (b). Myeloid cell emigration was determined by staining of lung sections with Cy3- labeled anti-GR1 antibodies (scale bar is $50 \mu \mathrm{m}$ ) followed by fluorescence microscopy (c). Shown are representative images from three independent experiments. Myeloid cell influx was quantified by analysis of 50 fields per group (d). Displayed is the average of GR1-positive cells per field using a 630 -fold magnification. *Significant differences between uninfected and infected samples; \#significant differences between untreated and treated samples (all $P<0.05$, ANOVA). untreated and pharmacologically treated wt and Asm-deficient mice after infecting them intravenously with $5 \times 10^{6} \mathrm{CFU}$ $S$. aureus. Wt mice died between 26 and $52 \mathrm{~h}$ after infection. Treatment of wt mice with amitriptyline delayed the death of the mice and the mice died between 50 and $85 \mathrm{~h}$ after infection. A very similar time course was observed for Asm-deficient mice that died between 50 and $80 \mathrm{~h}$ of infection. Treatment of wt mice with methicillin or vancomycin (1 and $9 \mathrm{~h}$ after infection and then twice daily) alone only rescued $50 \%$ mice (11-day observation period). In contrast, the treatment of wt mice with a combination of amitriptyline and antibiotics rescued $100 \%$ of infected wt mice, and no deaths were observed. Likewise, Asmdeficient mice under antibiotic intervention were also completely protected from sepsis-induced lethality (Fig. 8).

Next, we determined the number of bacteria in organs of the mice. As shown above (Fig. 7a; supporting Fig. 8A), these results showed lower bacterial numbers in liver, spleen, and lung of wt mice compared to Asm-deficient mice 12 and $24 \mathrm{~h}$ after infection.

In summary, these data indicate that the inhibition of lung edema in Asm-deficient or amitriptyline-treated mice together with a sufficient antibiotic treatment, which reduces the number of bacteria, but does not alter the effect of bacterial toxins released during the infection or even after antibiotic treatment, is able to completely protect from lethality of $S$. aureus sepsis.

\section{Discussion}

The results of the present study demonstrate that genetic deficiency or pharmacologic inhibition of the Asm/ceramide system protects against lung edema induced by systemic $S$. aureus infection. A principal hallmark of lung edema is degradation of TJ proteins, the disruption of endothelial cell 

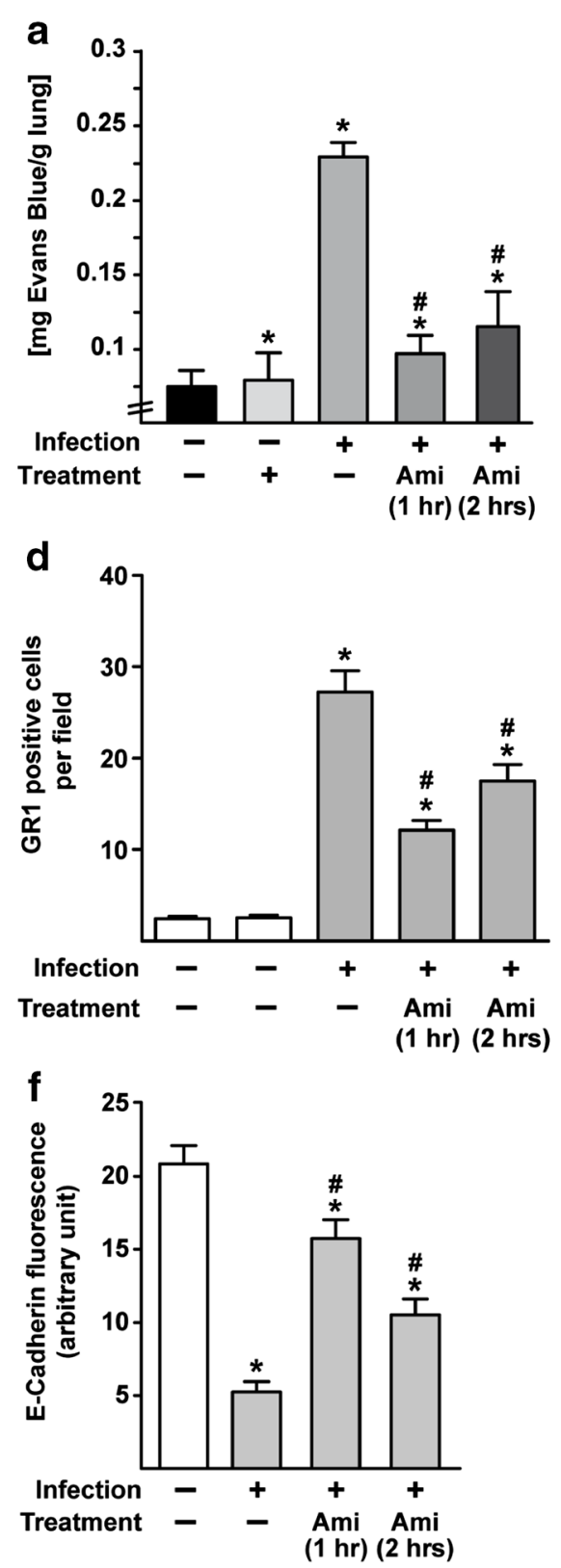

b

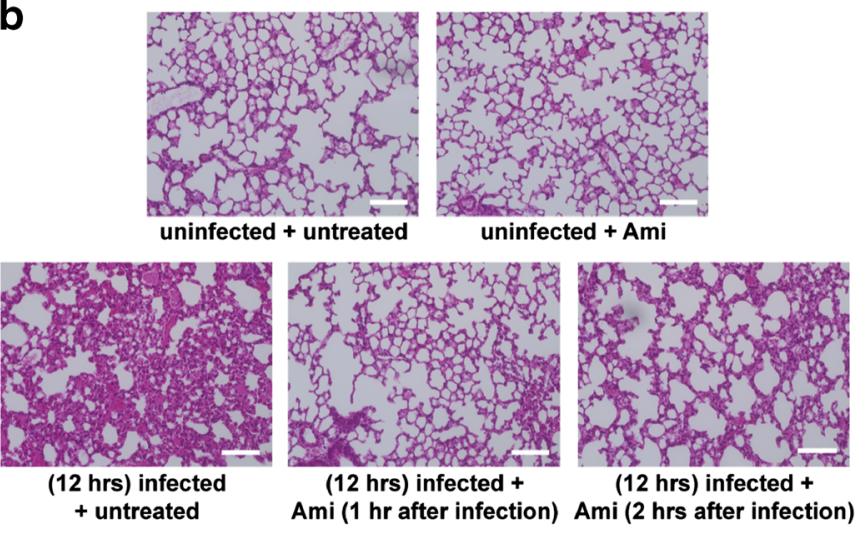

C
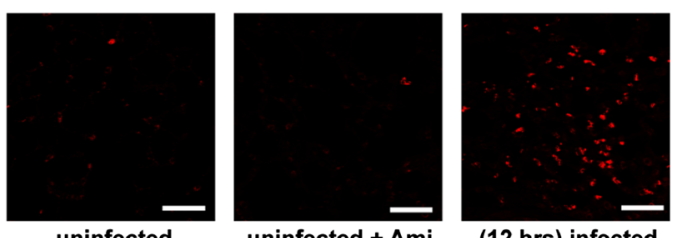

(12 hrs) infected

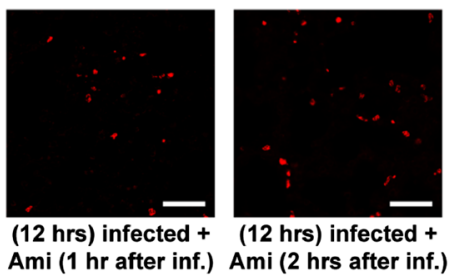

e

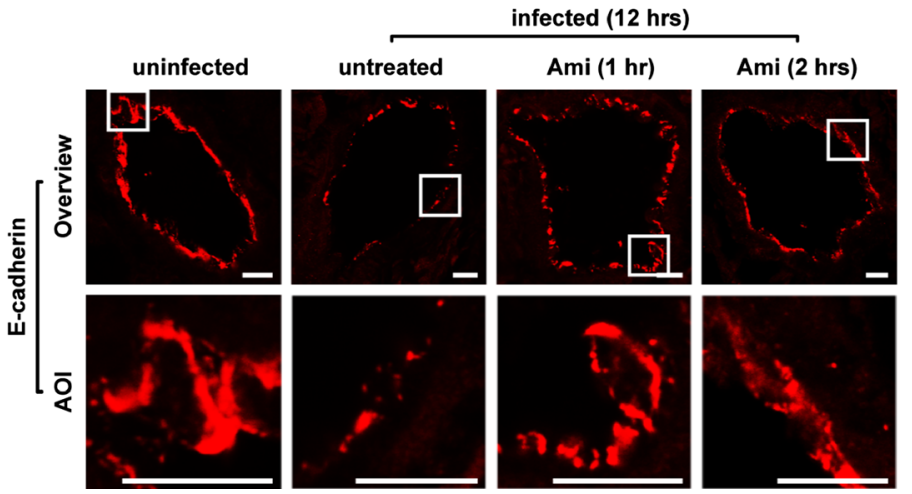

Fig. 6 Treatment of already infected mice with amitriptyline protects against lung edema (a-d). Wild-type (wt) mice were infected with S. aureus. Then 1 or $2 \mathrm{~h}$ later, they were i.p. injected with $16 \mathrm{mg} / \mathrm{kg}$ amitriptyline (Ami). The mice were sacrificed $12 \mathrm{~h}$ after infection. The lungs were removed and lung edema and myeloid cell trafficking were determined by extravasation of Evans Blue (a), or staining with H\&E (scale bar is $100 \mu \mathrm{m})(\mathbf{b})$ or with Cy3-labeled anti-GR1 antibodies (scale bar is $50 \mu \mathrm{m})(\mathbf{c})$. The average number of GR1-positive cells per field using a 630 -fold magnification was quantified by analysis of 50 fields per group (d). The breakdown of TJs was analyzed by staining lung sections with Cy3-labeled anti-E-cadherin antibodies (scale bar is $10 \mu \mathrm{m})(\mathbf{e})$. Panel (a) shows the mean \pm SD from four mice. Images in (b), (c), and (e) are representative from three independent experiments. TJ fluorescence was scored via Photoshop (ten pictures per mouse) (f). Data in (d) and (f) are shown as mean $\pm \mathrm{SD}, n=3$. *Significant differences between uninfected and infected samples; \#significant differences between treated and untreated samples (all $P<0.05$, ANOVA). integrity, and a resultant increase in vascular permeability and myeloid cell trafficking [6, 7]. All of these events are blocked in vivo and in vitro by genetic deficiency of Asm or treatment with the Asm inhibitor amitriptyline.

Our findings indicate that infection of endothelial cells with S. aureus activates Asm and thereby triggers the release of ceramide. Asm leads to the production of superoxide by endothelial cells. On the other hand, Asm activation is reduced by antioxidants, a result suggesting a positive feedback loop and a vicious cycle of $S$. aureus-induced Asm activation and superoxide release. This finding is similar to the results of previous studies showing a positive feedback loop between the Asm and 


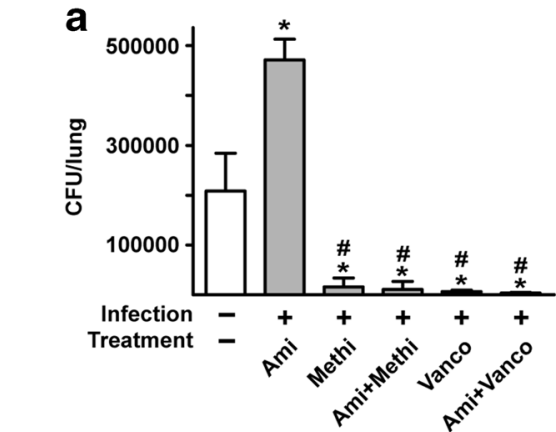

$$
\text { c }
$$
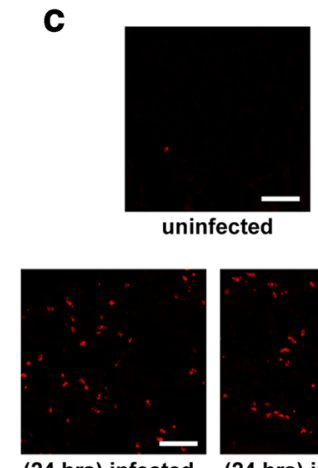

(24 hrs) infected + Methi

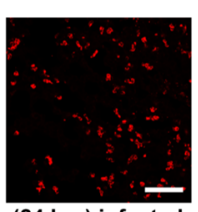

(24 hrs) infected

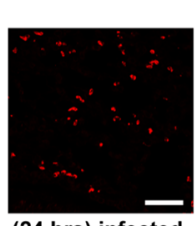

(24 hrs) infecte + Vanco

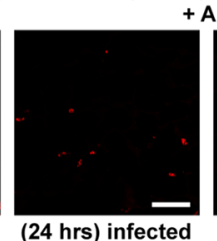
(24 hrs) infected
+ Ami + Methi

E-cadherin

\section{b}
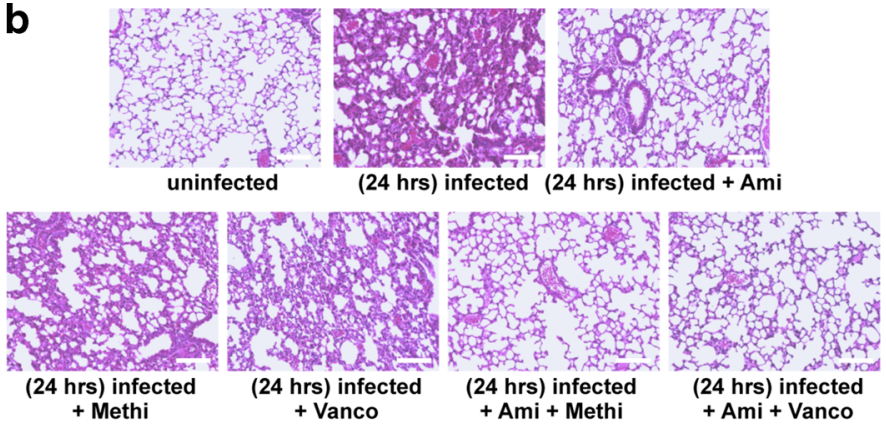

d

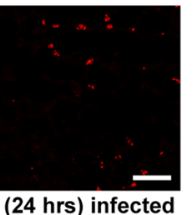

+ Ami

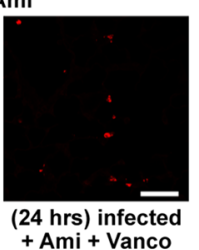

+ Ami + Vanco
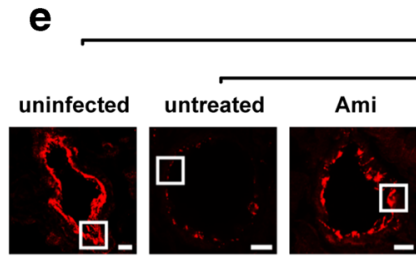

infected (24 hrs)
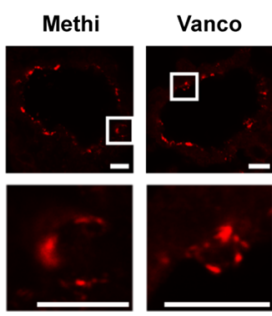

Fig. 7 The combination of amitriptyline and antibiotics cures $S$. aureus sepsis and inhibits lung edema Wt mice were infected with $S$. aureus. They were then left untreated, treated with an i.p. injection of amitriptyline $(A m i)(16 \mathrm{mg} / \mathrm{kg}) 1 \mathrm{~h}$ after infection, treated with either methicillin (Methi) or vancomycin (Vanco) (both $100 \mathrm{mg} / \mathrm{kg}$ ) 1 and $9 \mathrm{~h}$ after infection, or treated with the combination of amitriptyline and methicillin or vancomycin. The mice were sacrificed $24 \mathrm{~h}$ after infection. a Lungs were removed, homogenized, and lysed in saponin for the quantification of intracellular and extracellular bacteria (colonyforming units, $\mathrm{CFU}$ ) on lysogeny broth (LB) plates. Data shown are mean $\pm \mathrm{SD}$ of three independent experiments from the lung; very similar data were obtained for bacterial counts in the liver and spleen (not shown). *Significant differences between uninfected and infected samples; \#significant differences between treated and untreated samples $(P<0.05$,

superoxide after infection of macrophages with $P$. aeruginosa [30]. Recent studies showed that the translocation of lysosomal $\mathrm{V} 1 \mathrm{H}^{+}$-ATPase to the plasma membrane in coronary artery endothelial cells serves as a proton pump that contributes to the formation of small acidic regions at the cell surface. This shift in $\mathrm{pH}$ facilitates the activation of the Asm/ceramide system and leads to the formation of redox signalosomes, in which ceramide-enriched membrane domains are associated with the
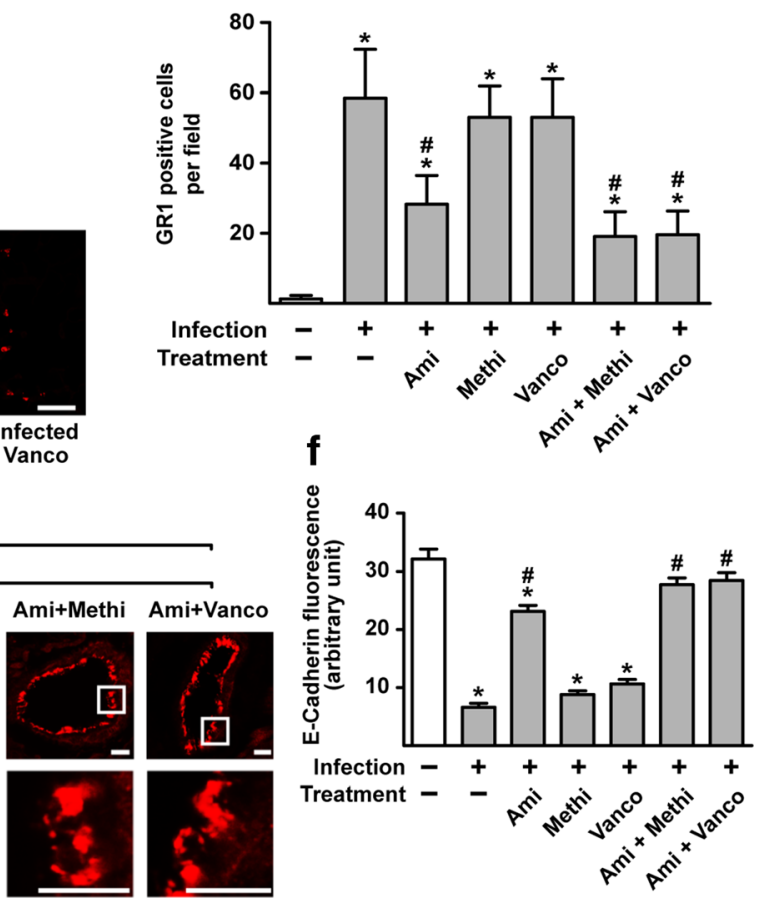

ANOVA). b Lungs from four mice per group were obtained after infection and subsequent treatment with the indicated drugs. Microscopic analysis of lung sections stained either with H\&E for lung edema (scale bar is $100 \mu \mathrm{m}$ ), with Cy3-labeled anti-GR1 antibody for myeloid cell trafficking (scale bar is $50 \mu \mathrm{m})(\mathbf{c})$, or for disruption of TJs with Cy3labeled anti-E-cadherin antibodies (e) (scale bar is $10 \mu \mathrm{m}$ ) was performed. Shown are representative images from three independent experiments by light transmission or confocal microscopy $(\mathbf{b}, \mathbf{c}, \mathbf{e})$. The average number of GR1-positive cells per field using a 630-fold magnification was analyzed of 50 fields per group (d). TJ fluorescence was scored via Photoshop (ten pictures per lung) (f). Data in (d) and (f) are shown as mean $\pm \mathrm{SD}, n=3$. *Significant differences between uninfected and infected samples; \#significant differences between treated and untreated samples (all $P<0.05$, ANOVA).

enhanced NADPH oxidase-mediated production of $\mathrm{O}_{2}^{-}[31$, 32]. A similar mechanism may apply to the activation of the Asm by $S$. aureus on the cell surface. Recent studies revealed that superoxide can directly downregulate $\mathrm{TJ}$ proteins and indirectly activate matrix metalloproteinases (MMPs) that contribute to disrupt the integrity of endothelial cell layers. Moreover, superoxide directly activates several inflammatory cytokines, which in turn activate MMPs [33-35]. 


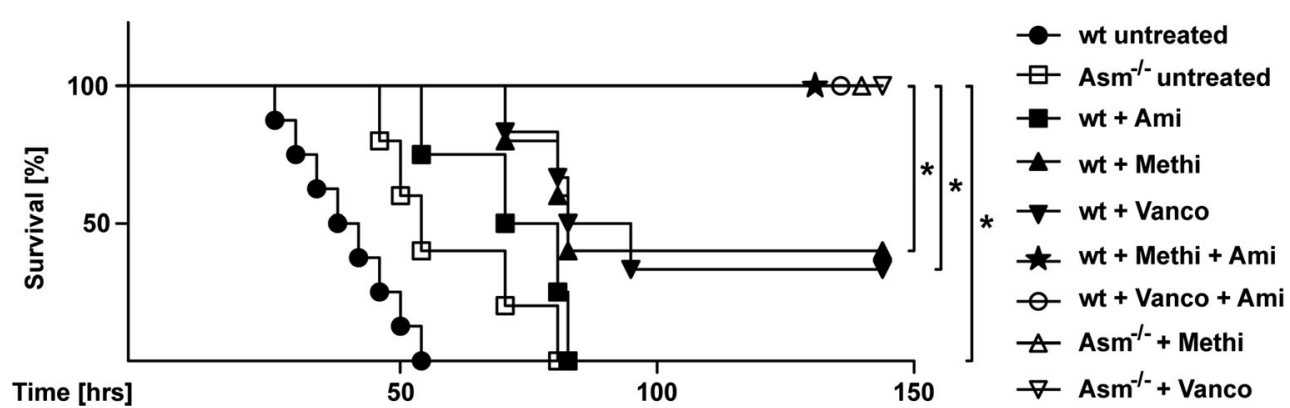

Fig. 8 The pharmacological treatment of lung edema and bacterial burden protects from lethality of $S$. aureus sepsis. For mortality experiments, wild-type (wt) and Asm-deficient $\left(\mathrm{Asm}^{-/}\right)$mice were infected intravenously with $5 \times 10^{6} \mathrm{CFU} S$. aureus. Mice were then left untreated or were pharmacologically treated with amitriptyline $(A m i)(1 \mathrm{~h}$ after infection, then twice daily), methicillin (Methi), or vancomycin (Vanco) (1 and $9 \mathrm{~h}$ after infection and then twice daily) or with a combination of amitriptyline and antibiotics. Survival was observed for up to 6 days. Data are shown in percent survival. Significance was determined by log-rank (Mantel-Cox) test.
$S$. aureus is a leading cause of septic infections, and S. aureus-induced sepsis is one of the most serious infections acquired in hospitals or in the community. However, even with the use of appropriate antibiotics, fatal lung edema often develops [27-29]. Interestingly, our studies with wt and Asmdeficient mice seem to mimic the situation in hospitals showing a high lethality in septic $S$. aureus infections even if adequately treated with antibiotics [27-29].

Our findings demonstrate that treating mice with amitriptyline 1 or $2 \mathrm{~h}$ after infection reduces $S$. aureus-induced pulmonary edema and also inhibits myeloid cell trafficking and the degradation of TJ proteins. The reduced capacity of mice treated with amitriptyline or Asm-deficient mice to kill $S$. aureus is consistent with the previous notion that myeloid cells lacking Asm are unable to cluster and activate NADPH oxidases resulting in a defect of the production of superoxide and a reduced killing of pathogens. Finally, amitriptyline-treated or Asm-deficient mice died by the inability to eliminate the bacteria. In contrast, antibiotics kill the bacteria, but did not reduce lung edema. Thus, the combination of amitriptyline and antibiotics combines the advantages of inhibiting lung edema and eliminating systemic bacteria, protecting mice from lethality.

These findings also suggest that the Asm is required to mediate the effects of at least some $S$. aureus strains. S. aureus expresses multiple toxins, such as alpha-toxin, PantonValentine leukocidin, and enterotoxin B and A, which cause membrane damage, infiltration of myeloid cells and macrophages, cytokine production, and increased vascular permeability resulting in severe pulmonary edema and lung injury [36-39]. Both of the $S$. aureus strains used in our study produce several hemolysins. The pore-forming alpha-toxin, which is one of the best-characterized virulence factors of S. aureus, is involved in the pathogenesis of skin infections, pneumonia, and sepsis, including those caused by MRSA. At present, it is unknown whether purified alpha-toxin activates the Asm in human and mouse monocytic cells. Recently, it was reported that the binding of alpha-toxin to its eukaryotic receptor A-disintegrin and metalloprotease 10 (ADAM10) leads to the up-regulation of ADAM10 activity, which is required for alpha-toxin-induced cytotoxicity [40-42]. Increased ADAM10 activity in epithelial and endothelial cells disrupts the cell barrier function, and this disruption contributes to the pathogenesis of lethal lung edema. However, it is unknown whether the Asm and ADAM10 function in the same signaling cascade or are independent pathways that are both required for the cellular effects of alpha-toxin.

Here, we demonstrated that the combination of amitriptyline and antibiotics effectively protects mice from lung edema and bacteremia during sepsis. Amitriptyline is a well-known antidepressant that has been widely used in clinical practice for more than 50 years and is associated with only mild adverse effects at therapeutic doses. Thus, inhibition of the Asm/ceramide system in combination with antibiotics could be a novel approach to treat severe systemic and often lethal infections and to inhibit lung injury in patients with incipient sepsis.

Acknowledgments We thank Matthias Soddemann, Simone Keitsch, and Melanie Kramer for excellent experimental support. The study was supported by Deutsche Forschungsgemeinschaft grants Gr 1697/2-1 to HG and grant $\mathrm{Gu} 335 / 16-2$ to EG, National Institutes of Health grants 2RO1HLO75316-05 to PLL and EG, and grant R01 GM107625-01A1 to TP and R01HL122937 to PLL and YZ.

Disclosure The authors declare that they have no conflict of interest.

Open Access This article is distributed under the terms of the Creative Commons Attribution License which permits any use, distribution, and reproduction in any medium, provided the original author(s) and the source are credited.

\section{References}

1. Lowy FD (1998) Staphylococcus aureus infections. N Engl J Med 20:520-532 
2. Chesney PJ (1983) Toxic-shock syndrome: a commentary and review of the characteristics of Staphylococcus aureus strains. Infection 11: 181-188

3. Barnett AG, Batra R, Graves N, Edgeworth J, Robotham J, Cooper B (2009) Using a longitudinal model to estimate the effect of methicillin-resistant Staphylococcus aureus infection on length of stay in an intensive care unit. Am J Epidemiol 170:1186-1194

4. Brun-Buisson C (1998) Methicillin-resistant Staphylococcus aureus: evolution and epidemiology, clinical impact, and prevention. Pathol Biol (Paris) 46:227-234

5. Klevens RM, Morrison MA, Nadle J, Petit S, Gershman K, Ray S, Harrison LH, Lynfield R, Dumyati G, Townes JM et al (2007) Invasive methicillin-resistant Staphylococcus aureus infections in the United States. Act Bacterial Core Surveill (ABCs) MRSA Investigators JAMA 298:1763-1771

6. Hocke AC, Temmesfeld-Wollbrueck B, Schmeck B, Berger K, Frisch EM, Witzenrath M, Brell B, Suttorp N, Hippenstiel S (2006) Perturbation of endothelial junction proteins by Staphylococcus aureus alpha-toxin: inhibition of endothelial gap formation by adrenomedullin. Histochem Cell Biol 126:305-316

7. Seeger W, Birkemeyer RG, Ermert L, Suttorp N, Bhakdi S, Duncker HR (1990) Staphylococcal alpha-toxin-induced vascular leakage in isolated perfused rabbit lungs. Lab Invest 63:341-349

8. Esen M, Schreiner B, Jendrossek V, Lang F, Fassbender K, Grassmé H, Gulbins E (2001) Mechanisms of Staphylococcus aureus induced apoptosis of human endothelial cells. Apoptosis 6:431-439

9. Schell-Toellner D, Wang K, Assi LK, Webb PR, Craddock RM, Salmon M, Lord JM (2004) Clustering of death receptors in lipid rafts initiates neutrophil spontaneous apoptosis. Biochem Soc Trans 32:679-81

10. Simons K, Ikonen E (1997) Functional rafts in cell membranes. Nature 387:569-72

11. Bock J, Gulbins E (2003) The transmembranous domain of CD40 determines CD40 partitioning into lipid rafts. FEBS Lett 534:169174

12. Grassmé H, Schwarz H, Gulbins E (2001) Molecular mechanisms of ceramide-mediated CD95 clustering. Biochem Biophys Res Commun 284:1016-1030

13. Utermöhlen O, Karow U, Löhler J, Krönke M (2003) Severe impairment in early host defense against Listeria monocytogenes in mice deficient in acid sphingomyelinase. J Immunol 170:2621-2628

14. McCollister BD, Myers JT, Jones-Carson J, Voelker DR, VázquezTorres A (2007) Constitutive acid sphingomyelinase enhances early and late macrophage killing of Salmonella enterica serovar typhimurium. Infect Immun 75:5346-5352

15. Grassmé H, Jendrossek V, Riehle A, von Kürthy G, Berger J, Schwarz H, Weller M, Kolesnick R, Gulbins E (2003) Host defense against Pseudomonas aeruginosa requires ceramide-rich membrane rafts. Nat Med 9:322-330

16. Utermöhlen O, Herz J, Schramm M, Krönke M (2008) Fusogenicity of membranes: the impact of acid sphingomyelinase on innate immune responses. Immunbiology 213:307-314

17. Grassmé H, Gulbins E, Brenner B, Ferlinz K, Sandhoff K, Harzer K, Lang F, Meyer TF (1997) Acidic sphingomyelinase mediates entry of N. gonorrhoeae into nonphagocytic cells. Cell 91:605-615

18. Haimovitz-Friedmann A, Cordon-Cardo C, Bayoumy S, Garzotto M, McLoughlin M, Gallily R, Edwards CK 3rd, Schuchman EH, Fuks Z, Kolesnick R (1997) Lipopolysaccharide induces disseminated endothelial apoptosis requiring ceramide generation. J Exp Med 186: 1831-1841

19. Zhang Y, Li X, Carpenteiro A, Gulbins E (2008) Acid sphingomyelinase amplifies redox signaling in Pseudomonas aeruginosa-induced macrophage apoptosis. J Immunol 181:4247-4254

20. Pai AB, Patel H, Prokopienko AJ, Alsaffar H, Gertzberg N, Neumann P, Punjabi A, Johnson A (2012) Lipoteichoic acid from
Staphylococcus aureus induces lung endothelial cell barriers dysfunction: role of reactive oxygen and nitrogen species. PLoS One 7: e49209

21. Meyer JW, Holland JA, Ziegler LM, Chang MM, Beebe G, Schmitt ME (1999) Identification of a functional leukocyte-type NADPH oxidase in human endothelial cells: a potential atherogenic source of reactive oxygen species. Endothelium 7:11-22

22. Koedel U, Pfister HW (1999) Oxidative stress in bacterial meningitis. Brain Pathol 9:57-67

23. Schirmer RH, Schöllhammer T, Eisenbrand G, Krauth-Siegel RL (1987) Oxidative stress as a defense mechanism against parasitic infections. Free Radic Res Commun 3:3-12

24. Kornhuber J, Tripal P, Reichel M, Terfloth L, Bleich S, Wiltfang J, Gulbins E (2008) Identification of new functional inhibitors of acid sphingomyelinase using a structure-property-activity relation model. J Med Chem 51:219-237

25. Christy JP, Lupinetti FM, Mardan AH, Thompson SA (1991) Endothelial cell viability in the rat aortic wall. Ann Thorac Surg 51: 204-7

26. Hurwitz R, Ferlinz K, Sandhoff K (1994) The tricyclic antidepressant desipramine causes proteolytic degradation of lysosomal sphingomyelinase in human fibroblasts. Biol Chem Hoppe Seyler 375:447-50

27. Moore CL, Lu M, Cheema F, Osaki-Kiyan P, Perri MB, Donabedian S, Haque NZ, Zervos MJ (2011) Prediction of failure in vancomycintreated methicillin-resistant Staphylococcus aureus bloodstream infection: a clinically useful risk stratification tool. Antimicrob Agents Chemother 55:4581-4588

28. Moore CL, Osaki-Kiyan P, Haque NZ, Perri MB, Donabedian S, Zervos MJ (2012) Daptomycin versus vancomycin for bloodstream infections due to methicillin-resistant Staphylococcus aureus with a high vancomycin minimum inhibitory concentration: a case-control study. Clin Infect Dis 54:51-58

29. Kanafani ZA, Kourany WM, Fowler VG Jr, Levine DP, Vigliani GA, Campion M, Katz DE, Corey GR, Boucher HW (2009) Clinical characteristics and outcomes of diabetic patients with Staphylococcus aureus bacteremia and endocarditis. Eur J Clin Microbiol Infect Dis 28:1477-1482

30. Zhang Y, Li X, Grassmé H, Döring G, Gulbins E (2010) Alterations in ceramide concentration and $\mathrm{pH}$ determine the release of reactive oxygen species by Cftr-deficient macrophages on infection. J Immunol 184:5104-5111

31. Xu M, Xia M, Li XX, Han WQ, Boini KM, Zhang F, Zhang Y, Ritter JK, Li PL (2012) Requirement of translocated lysosomal V1 $\mathrm{H}(+)$-ATPase for activation of membrane acid sphingomyelinase and raft clustering in coronary endothelial cells. Mol Biol Cell 23:1546-1557

32. Xu M, Li XX, Ritter JK, Abais JM, Zhang Y, Li PL (2013) Contribution of NADPH oxidase to membrane CD38 internalization and activation in coronary arterial myocytes. PLoS One 7:e71212

33. Gy Y, Dee CM, Shen J (2011) Interaction of free radicals, matrix metalloproteinases and caveolin-1 impacts blood-brain barrier permeability. Front Biosci (Schol Ed) 1:1216-31

34. Abdul-Muneer PM, Chandra N, Haora J (2014) Interactions of oxidative stress and neurovascular inflammation in the pathogenesis of traumatic brain injury. Mol Neurobiol 28 (Epub ahead of print)

35. Rochfort KD, Collins LE, Murphy RP, Cummins PM (2014) Downregulation of blood-brain barrier phenotype by proinflammatory cytokines involves NADPH oxidase-dependent ROS generation: consequences for interendothelial adherens and tight junctions. PLoS One 3:e101815

36. Ménoret A, Kumar S, Vella AT (2012) Cytochrome b5 and cytokeratin 17 are biomarkers in bronchoalveolar fluid signifying onset of acute lung injury. PLoS One 7:e40184 
37. Diep BA, Chan L, Tattevin P, Kajikawa O, Martin TR, Basuino L, Mai TT, Marbach H, Braughton KR, Whitney AR et al (2010) Polymorphonuclear leukocytes mediate Staphylococcus aureus Panton-Valentine leukocidin-induced lung inflammation and injury. Proc Natl Acad Sci U S A 107:5587-5592

38. Mattix ME, Hunt RE, Wilhelmsen CL, Johnson AJ, Baze WB (1995) Aerosolized staphylococcal enterotoxin B-induced pulmonary lesions in rhesus monkeys (Macaca mulatta). Toxicol Pathol 23:262268

39. Bhakdi S, Suttorp N, Seeger W, Füssle R, Tranum-Jensen J (1984) Molecular basis for the pathogenicity of $S$. aureus alpha-toxins. Immun Infekt 12:279-285
40. Inoshima I, Inoshima N, Wilke GA, Powers ME, Frank KM, Wang Y, Bubeck Wardenburg J (2011) A Staphylococcus aureus pore-forming toxin subverts the activity of ADAM10 to cause lethal infection in mice. Nat Med 17:1310-1314

41. Powers ME, Kim HK, Wang Y, Bubeck Wardenburg J (2012) ADAM10 mediates vascular injury induced by Staphylococcus aureus $\alpha$-hemolysin. J Infect Dis 206:352-356

42. Wilke GA, Bubeck Wardenburg J (2010) Role of a disintegrin and metalloprotease 10 in Staphylococcus aureus $\alpha$-hemolysin-mediated cellular injury. Proc Natl Acad Sci U S A 107:13473-13478

43. Duthie ES, Lorenz LL (1952) Staphylococcal coagulase; a model of action and antigenicity. J Gen Microbiol 6:95-107 